This PDF is a selection from a published volume from the National Bureau of Economic Research

Volume Title: Labor Markets and Firm Benefit Policies in Japan and the United States

Volume Author/Editor: Seiritsu Ogura, Toshiaki Tachibanaki and David A. Wise, editors

Volume Publisher: University of Chicago Press

Volume ISBN: 0-226-62094-8

Volume URL: http://www.nber.org/books/ogura03-1

Conference Date: January 20-23, 2000

Publication Date: January 2003

Title: Why Do the Japanese Spend So Much on Drugs?

Author: Seiritsu Ogura, Takehiko Hagino

URL: http://www.nber.org/chapters/c10309 


\title{
Why Do the Japanese Spend So Much on Drugs?
}

\author{
Seiritsu Ogura and Takehiko Hagino
}

\subsection{Introduction}

In Japan, drugs account for an enormous proportion of health care costs. Of the five major developed countries listed in table 9.1, Japan and France have the highest absolute per-patient cost of drugs, spending three times as much as England, twice as much as the United States, and one and a half times as much as Germany. Japan consistently ranks at the top in terms of the share of drugs in total health care costs, spending more than 20 percent on drugs according to the Organization for Economic Cooperation and Development (OECD) Health Data (1998, table 9.2).

According to the 1996 Survey on Socialized Medicine (Ministry of Health and Welfare 1994-1996) ${ }^{1}$ injections account for as great a share of inpatient costs as do surgeries ( 9.5 percent and 9.4 percent, respectively), while drugs and injections together consume 39.6 percent of outpatient health care costs. Although drugs are a very important component of total health care expenditures in Japan, their importance seems to be heavily concentrated in the outpatient care of elderly patients. In inpatient care, drugs account for only 12.8 percent of the difference in average costs between the elderly and the rest of the population. In outpatient care, drugs account for 56 percent of this difference. Given the rapid aging of the Japanese population, it is clear that if we do not find some way to control

Seiritsu Ogura is professor of economics at Hosei University in Tokyo. Takehiko Hagino was an economist at the Japan Center for Economic Research when this paper was written.

The authors wish to thank the Japan Center for Global Partnership and the Toyota Foundation for financial support, and Mark McClellan for helpful comments. This paper is a revised version of the Ogura-Hagino report (in Japanese) contained in Takayama (1999).

1. This survey, based on approximately 300,000 reimbursement claims submitted by health care providers, is published annually by the Ministry of Health and Welfare. 
International Health Care and Drug Expenditures, 1993

\begin{tabular}{lcccc}
\hline & $\begin{array}{c}\text { National Health } \\
\text { Care Expenditures } \\
\text { (yen per capita) }\end{array}$ & $\begin{array}{c}\text { Outpatient Drug } \\
\text { Expenditures } \\
\text { (yen per patient) }\end{array}$ & $\begin{array}{c}\text { Inpatient Drug } \\
\text { Expenditures } \\
\text { (yen per patient) }\end{array}$ & $\begin{array}{c}\text { Share of All Drugs } \\
\text { in National Health } \\
\text { Care Expenditure } \\
\text { (\%) }\end{array}$ \\
\hline France & 253,680 & 43,375 & 50,375 & 19.9 \\
Germany & 224,420 & 32,195 & 38,283 & 17.1 \\
England & 110,625 & 16,341 & 18,153 & 16.4 \\
United States & 312,755 & 23,076 & 35,418 & 11.3 \\
Japan & 195,217 & 43,533 & 57,589 & 29.5 \\
\hline
\end{tabular}

Source: Illustrated White Paper on Health Insurance (1998).

Note: Data for England are from 1992. Exchange rates: 23 yen/franc, 79 yen/deutsche mark, 231 yen/pound, and 122 yen/dollar.

Table 9.2 Share of Drugs in National Health Care Costs, 1990-1998 (\%)

\begin{tabular}{lrrrrrrrr}
\hline & 1990 & 1991 & 1992 & 1993 & 1994 & 1995 & 1996 & 1997 \\
\hline France & 16.7 & 16.7 & 16.6 & 16.8 & 16.6 & 16.7 & 17.0 & 16.7 \\
Germany & 14.2 & 14.3 & 14.2 & 12.4 & 12.3 & 12.3 & 12.7 & 12.6 \\
England & 13.8 & 14.0 & 14.5 & 15.3 & 15.3 & 15.9 & 16.5 & 17.3 \\
United States & 8.6 & 8.5 & 8.5 & 8.4 & 8.4 & 8.6 & 8.8 & 7.8 \\
Japan & 21.4 & 22.8 & 21.9 & 22.1 & 20.9 & 20.2 & 20.8 & 20.0 \\
\hline
\end{tabular}

Source: 1998 OECD Health Data

the cost of drugs, we will not be able to control health care expenditures in the twenty-first century.

Why do we spend so much on drugs? The first place to look for an answer is in the enormous distortions generated by drug price regulations during the last five decades. Although the entire health care sector lies outside the realm of the market economy (the government sets comprehensive reimbursement prices for individual health care services in an attempt to control every possible aspect of health care service delivery), these regulations on drug prices are very peculiar. Regulated drug prices vary by brand name even if they are chemically identical. In general, when the government purchases any other good or service it must observe a set of very stringent procurement procedures designed to assure the lowest possible price. With drugs, physicians are allowed to use more expensive brandname drugs when cheaper alternatives are available, even though they are supposed to be acting as agents of the government.

Second, the government sets reimbursement (retail) prices on the basis of market (wholesale) prices from almost eighteen months earlier, and these retail prices are then fixed for the following two years. If the market functioned normally, such regulation would be a source of enormous risk 
for health care providers. In other words, the market structure must be very peculiar for such a system to have functioned without driving a large number of providers to bankruptcy.

Third, drug markets are very tightly regulated and protected by extremely high barriers to new entry. The regulations concerning the introduction of new drugs work as prohibitive barriers to entry, as they are both very time consuming and costly. At the same time, these high barriers make it easy for insiders to set noncompetitive prices and to build cozy relationships with regulators.

In this paper, we present evidence regarding the effects of price distortions on resource allocation in the health care sector. Our estimates indicate that the magnitude of these effects exceeds 20 percent, and may be as high as 50 percent, of drug costs. We then show that the government's attempts to control drug prices directly are at best ineffective, as they have been offset by drug-switching effects in most drug groups. These drugswitching effects are in turn induced by the built-in profit margins for "new" drugs, which are generously priced by regulators. We base our conclusions on statistical analyses of the first comprehensive microdata set compiled in Japan.

The rest of the paper proceeds as follows: In section 9.2, we review the drug price controls of the last decade and classify the economic inefficiencies associated with these controls; in section 9.3, we analyze the drug selection behavior of physicians; in section 9.4, we present a decomposition analysis of drug costs; in section 9.5, we discuss various reform proposals currently under consideration; section 9.6 concludes.

\subsection{Drug Pricing in the Japanese Health Care System}

As all drugs are privately produced, health care service providers must purchase all necessary drugs through the market. Trading is free for almost all drugs, and market prices are formed on the basis of reimbursement prices. In effect, the reimbursement prices are the drugs' retail prices and market prices are the drugs' wholesale prices, generating profit margins for each drug.

\subsubsection{Formula for Drug Price Revisions}

The Ministry of Health and Welfare (MHW) updates the list of reimbursement prices for individual drugs approximately every two years using its Survey of Drug Prices. ${ }^{2}$ The current list of drugs contains almost 14,000

2. In the Survey of Drug Prices, the government collects data on the actual purchase prices of individual drugs from health care providers. The survey's objectivity, however, is somewhat weakened because it is announced well in advance and data are collected for just one month (usually September). 
different drugs. For nearly ten years, the government has been using the following formula to revise the reimbursement prices: ${ }^{3}$

$$
Y_{t}=X_{t-1}+r_{t} Y_{t-1} \text {, }
$$

where

$Y_{t}:$ New drug price,

$X_{t-1}$ : Average market price in the Survey of Drug Prices,

$r_{t}$ : Reasonable zone factor $\left(0<r_{t}<1\right)$, and

$Y_{t-1}$ : Old drug price.

Once a new price is set, it is fixed for the next two years. Hence, at least in theory, providers take on the considerable risk of market price variation in drug prices. In the last ten years of practice, however, once the new prices are announced almost all market prices have continuously declined. As a result, providers enjoy positive profit margins on almost all drugs and so have an economic incentive to sell as many drugs as possible to their patients. There are two reasons for this: the reasonable zone factor and the generous price setting for "new" drugs.

\subsubsection{Drug Pricing Rules}

If we subtract old drug prices from both sides of equation (1), we obtain

$$
Y_{t}-Y_{t-1}=-\left(Y_{t-1}-X_{t-1}\right)+r_{t} Y_{t-1} \text {. }
$$

By dividing both sides by old drug prices, we obtain the revision formula in proportion terms

$$
y_{t-1}=-\pi_{t-1}+r_{t},
$$

where $y_{t-1}$ is the rate of change of the reimbursement price of the drug and $\pi_{t-1}$ is the discount rate the firm offered to providers in the previous period.

$$
\begin{gathered}
y_{t-1}=\frac{\left(Y_{t}-Y_{t-1}\right)}{Y_{t-1}} \\
\pi_{t-1}=\frac{\left(Y_{t-1}-X_{t-1}\right)}{Y_{t-1}}
\end{gathered}
$$

In the absence of the reasonable zone factor, equation (5) implies that if a firm offers a discount to promote the sale of a drug, that drug's price is permanently lowered. Such a prospect should make the firm hesitant to offer a discount. With the reasonable zone factor, however, the firm can offer price discounts without endangering future profitability, provided that the discount rate remains within the range of the reasonable zone factor. 
Recently, however, the government has been forced to rapidly reduce both drug prices ${ }^{4}$ and reasonable zone factors in an attempt to control health care costs, particularly those of the elderly. The zone factor dropped from 15 percent in 1992 to 13 percent in 1994, 11 percent in 1996, 10 percent in 1997, and 5 percent in 1998. Starting in 1997, an even lower rate was applied to "new" drugs with chemical components similar to existing drugs: 8 percent in 1997 and 2 percent in 1998.

\subsubsection{Assessing Price Regulations: Decomposition of the Variation in the Cost of Drugs}

As we have shown, Japanese drug price regulation has a built-in price reduction mechanism. If there were no change in quantity used, price would change at exactly the same rate as cost. The overall cost of drugs in public health insurance, however, follows two-year cycles, showing decreases in the years of price revisions and increases in the years following price revisions (table 9.3). Many (Ikegami et al. 1998; Ogura 1996, 1998) believe that this pattern is explained by the combination of two trends working against the cut in drug prices: increasing reliance on multiple drugs and overall switching to more expensive drugs. Some add a third trend of switching to new expensive drugs. As far as we know, however, no one has quantified these trends using comprehensive drug-usage data.

\section{Five-Factor Decomposition}

We decompose the variation in drug costs using the following five factors: (a) prescription probability factor; (b) drug-switching factor; (c) price regulation factor; (d) daily quantity factor; and (e) number of days prescribed factor. All drugs are classified at the three-digit level. The perpatient average cost of drugs in group $k$ in period $t$ is denoted $v_{k}(t) ; v_{k}(t)$ is the product of $\Gamma_{k}(t)$, the probability that any drug in group $k$ is prescribed; and $\Omega_{k}(t)$ is the per-patient cost of drugs in group $k$ (given that at least one drug in the group has been prescribed). Therefore, we have

$$
\begin{aligned}
& V(t)=\sum_{k=1}^{n} v_{k}(t) \\
& v_{k}(t)=\Gamma_{k}(t) \Omega_{k}(t) .
\end{aligned}
$$

The per-patient cost, $\Omega_{k}(t)$, is in turn the product of four factors (summed over all $i$ ): $s_{i}(t)$, the probability of selecting drug $i$ in group $k ; p_{i}(t)$, the reimbursement price of drug $i ; x_{i}(t)$, the daily quantity of $\operatorname{drug} i$; and $d_{i}(t)$, the number of days that drug $i$ is used. Or,

$$
\Omega_{k}(t)=\sum_{i} s_{i}(t) p_{i}(t) x_{i}(t) d_{i}(t)
$$

4. For the officially announced changes in drug prices, see table 9.3 . 


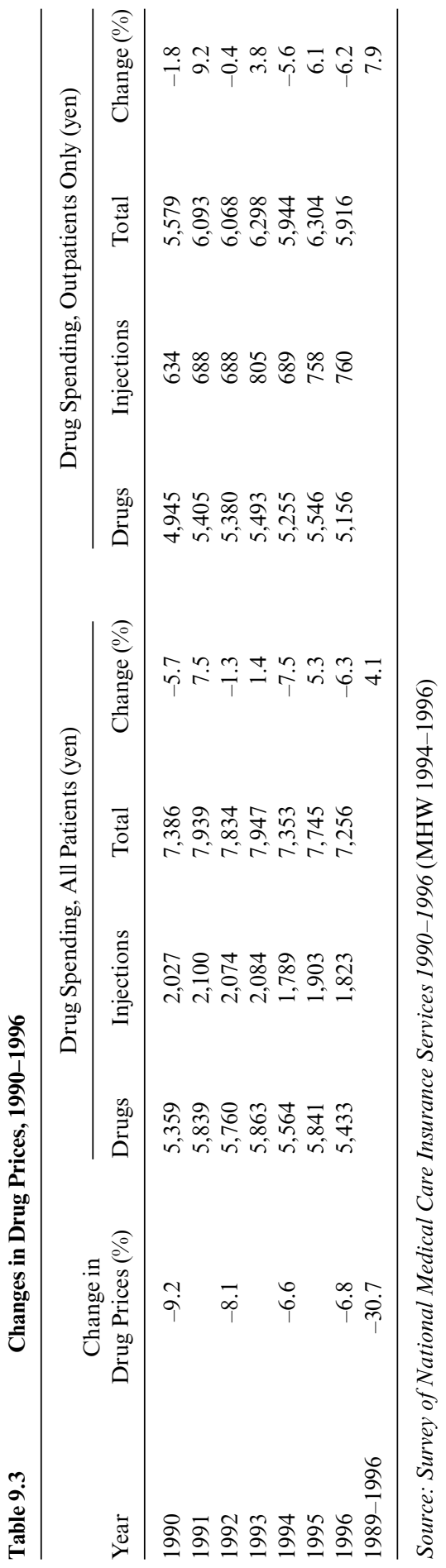


Note that the sum of the $s_{i}(t)$ terms, each of which represents the probability of selecting drug $i$ conditional on prescribing some drug in group $k$, equals one.

Given the above formulation, the variation in $v_{k}(t)$ is determined by the variation in the five component variables. The proportional rate of change in $v_{k}(t)$ is given by

$$
\begin{aligned}
\frac{\Delta v_{k}(t)}{v_{k}(t)}= & \frac{\Delta \Gamma_{k}(t)}{\Gamma_{k}(t)}+\frac{\Delta \Omega_{k}(t)}{\Omega_{k}(t)}=\frac{\Delta \Gamma_{k}(t)}{\Gamma_{k}(t)}+\frac{\sum_{i} \Delta s_{i}(t) p_{i}(t) x_{i}(t) d_{i}(t)}{\sum_{i} s_{i}(t) p_{i}(t) x_{i}(t) d_{i}(t)} \\
& +\frac{\sum_{i} s_{i}(t) \Delta p_{i}(t) x_{i}(t) d_{i}(t)}{\sum_{i} s_{i}(t) p_{i}(t) x_{i}(t) d_{i}(t)}+\frac{\sum_{i} s_{i}(t) p_{i}(t) \Delta x_{i}(t) d_{i}(t)}{\sum_{i} s_{i}(t) p_{i}(t) x_{i}(t) d_{i}(t)} \\
& +\frac{\sum_{i} s_{i}(t) p_{i}(t) x_{i}(t) \Delta d_{i}(t)}{\sum_{i} s_{i}(t) p_{i}(t) x_{i}(t) d_{i}(t)} .
\end{aligned}
$$

In words, we offer the following explanation:

1. The first term is the rate of change in the probability of prescribing drugs in group $k$. The trend toward relying on more groups of drugs is found by summing the first term over all the drug groups.

2. The second term is the drug-switching effect within group $k$, or the rate of change in the per-patient cost of drugs as a result of changes in drug selection. The trend of switching to expensive drugs is observed directly in the second term.

3. The third term is the price regulation effect in group $k$, or the rate of change in the per-patient cost of drugs as a result of changes in regulated drug prices. This is the government's control variable, and the sum of the third term over all the drug groups should be close to the rate the government announces.

4. The fourth term is the rate of change in the per-patient cost of drugs as a result of changes in daily quantities.

5. The fifth term is the rate of change in the per-patient cost of drugs as a result of changes in the number of days for which drugs are prescribed.

\section{Data: Modification and Errors}

We use the 1994, 1995, and 1996 Survey of Drugs for our analysis (MHW). The data are described in detail in section 9.3.2. There are two groups of claims that are dropped from the original data sets. First, we exclude all claims submitted by drug stores because they do not include patient identification numbers. Second, we exclude observations above the 99th percentile in each three-digit group in terms of daily quantities. We make this exclusion because of the extremely large variance in daily quantities for some groups. The descriptive statistics for our sample are given in table 9.4. 


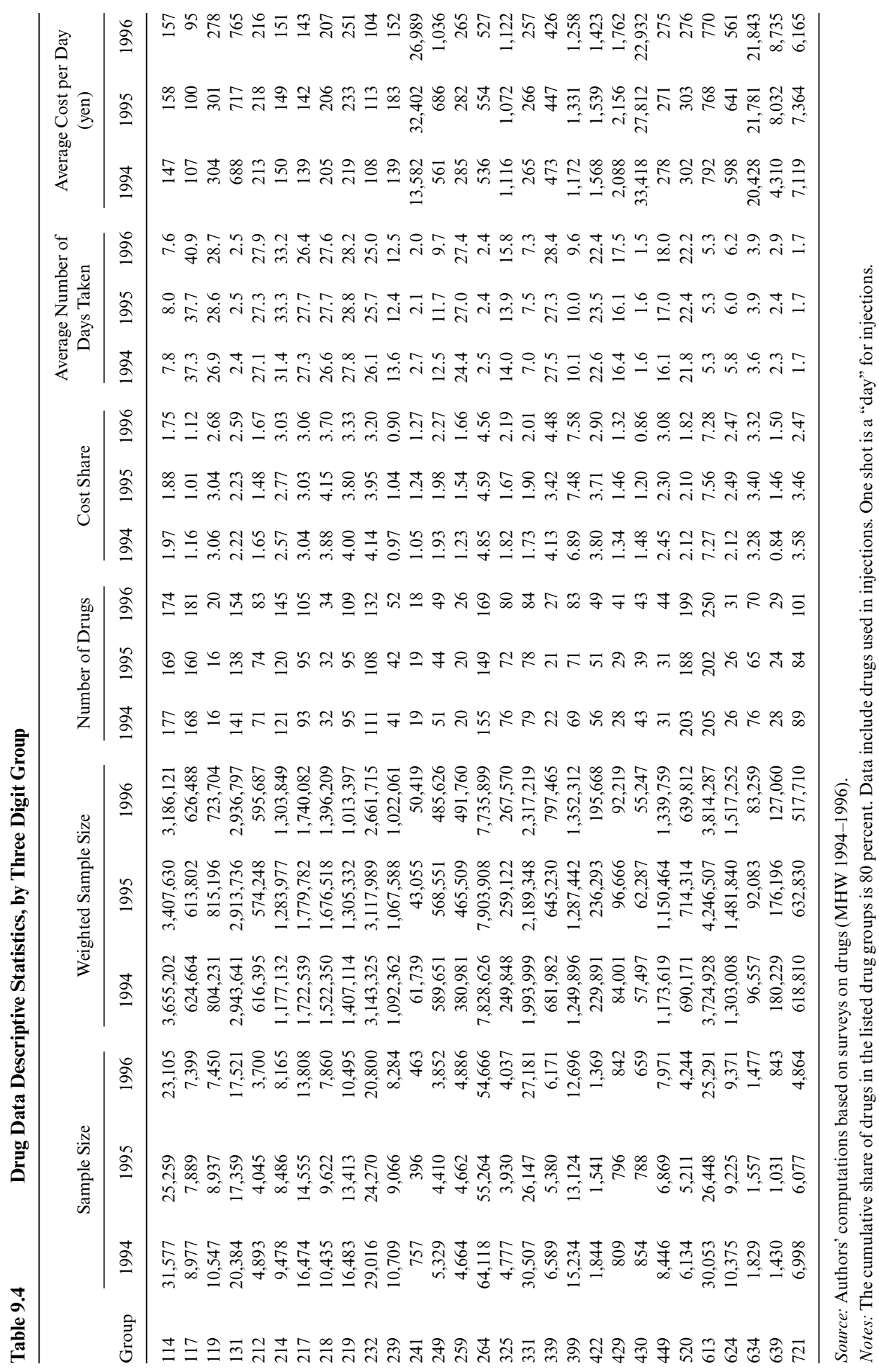


We still have to deal with two problems that plague any attempt to use indexes: what to do with drugs introduced into and removed from our sample. Drugs that are introduced for the first time in period $t$ do not have data in period $t-1$, including price data. Drugs that are removed in period $t$ do not have data in period $t+1$, including price data. If we exclude both of them, we lose a significant part of total drug costs from our analysis, but if we include them we will no longer have an identity.

In the end, we have chosen inclusion with some modification. For the prescription factor and the drug-switching factor terms, we include both introduced and removed drugs. For the price regulation factor, daily quantity factor, and number of days prescribed factor terms, we include neither. This is the main reason for the nonnegligible residuals obtained in the decomposition analysis in certain cases.

\section{Results}

The decomposition analyses have been carried out for all three-digit groups. Table 9.5 reports aggregated results (the sum of all drugs) with breakdowns for some provider and regional characteristics.

Results for All Drugs. Between 1994 and 1995, when there were no revisions of drug prices, the average cost of drugs increased by 5.1 percent. According to our decomposition, changes in the prescription probability increased the cost of drugs by 1.7 percent. The drug-switching effect increased the cost of drugs by 5.4 percent, while changes in daily quantities decreased the cost of drugs by 0.7 percent. Finally, changes in the number of days prescribed increased the cost of drugs by 1.5 percent. The errors therefore amount to -2.8 percent.

Between 1995 and 1996, when drug prices were revised, average drug costs fell by 9.7 percent. The reduction in drug prices decreased the cost of drugs by 7.7 percent, and changes in the prescription probability decreased the cost of drugs another 7.0 percent. The drug-switching effect increased the cost of drugs by 7.1 percent, changes in daily quantity increased the cost of drugs by 0.2 percent, and changes in the number of days prescribed decreased the cost of drugs by 0.1 percent.

Price Controls and Drug-switching Effects. The magnitudes of drugswitching effects are particularly important as an indicator of the effectiveness of drug price regulation. In table 9.6 we report the percentage changes in price in 1996 for ten major three-digit groups, as well as the drugswitching effects in 1995 and 1996. Our ten major groups account for almost 40 percent of the cost of drugs in 1995, and changes in their prices were enough to drive drug costs down by 3.3 percent. However, the drugswitching effects in these groups in 1995 and 1996 together drove drug costs 


\begin{tabular}{|c|c|c|c|c|c|c|c|}
\hline & $\begin{array}{c}\text { Change } \\
\text { in Total } \\
\text { Drug } \\
\text { Costs }\end{array}$ & $\begin{array}{l}\text { Change in } \\
\text { Prescription } \\
\text { Probability }\end{array}$ & $\begin{array}{c}\text { Drug } \\
\text { Switching } \\
\text { Effect }\end{array}$ & $\begin{array}{c}\text { Change } \\
\text { in Drug } \\
\text { Prices }\end{array}$ & $\begin{array}{l}\text { Change } \\
\text { in Daily } \\
\text { Quantity }\end{array}$ & $\begin{array}{c}\text { Change } \\
\text { in Number } \\
\text { of Days } \\
\text { Taken }\end{array}$ & Error \\
\hline \multicolumn{8}{|c|}{ 1994-1995 } \\
\hline Total & 5.1 & 1.7 & 5.4 & & -0.7 & 1.5 & -2.8 \\
\hline Inpatient care & 5.1 & 0.8 & 5.4 & & -1.5 & 1.9 & -1.6 \\
\hline Outpatient care & 5.1 & 1.5 & 8.3 & & 0.9 & 1.4 & -7.0 \\
\hline \multicolumn{8}{|l|}{ Ownership } \\
\hline National/public & 4.9 & 4.7 & 4.4 & & 2.7 & 3.1 & -9.9 \\
\hline Private & 4.2 & 2.5 & 6.8 & & 5.1 & 1.5 & -11.6 \\
\hline University & -11.3 & 9.9 & 22.3 & & -0.8 & -1.5 & -41.2 \\
\hline Clinic with beds & 0.8 & -1.6 & 4.4 & & -1.4 & 7.3 & -8.0 \\
\hline Clinic without beds & 6.8 & 4.3 & 6.3 & & 9.1 & 3.6 & -16.5 \\
\hline \multicolumn{8}{|l|}{ Number of beds } \\
\hline 0 & 4.2 & 3.8 & 6.1 & & 5.9 & 2.3 & -14.0 \\
\hline$<200$ & 5.4 & 3.4 & 3.0 & & -2.6 & 10.9 & -9.3 \\
\hline$>200$ & 1.7 & 2.4 & 7.2 & & 10.7 & 0.2 & -18.9 \\
\hline \multicolumn{8}{|l|}{$\begin{array}{c}\text { Number of patients } \\
\text { per physician }\end{array}$} \\
\hline$<100$ & 0.7 & -0.9 & 2.0 & & 15.4 & 2.1 & -17.9 \\
\hline $100-200$ & 7.9 & 6.3 & 13.4 & & 1.0 & 1.5 & -14.4 \\
\hline$>200$ and $<400$ & 16.3 & 10.9 & 4.1 & & -0.2 & 6.5 & -5.0 \\
\hline$>400$ & 9.0 & 12.4 & 51.7 & & -3.1 & -0.9 & 51.1 \\
\hline \multicolumn{8}{|l|}{ Region } \\
\hline Hokkaido & -0.2 & 14.1 & 9.0 & & -3.5 & 3.7 & -23.6 \\
\hline Tohoku & 8.1 & 8.9 & 13.0 & & -1.0 & -1.4 & -11.4 \\
\hline Kanto & -7.3 & 2.6 & 1.1 & & 12.9 & -3.3 & -20.7 \\
\hline Hokuriku & -24.9 & -6.4 & 27.5 & & -1.4 & 3.4 & -48.0 \\
\hline Chubu-Tokai & 8.2 & 4.4 & 28.4 & & -3.1 & 3.6 & -25.3 \\
\hline Kinki & 12.1 & 3.0 & 11.2 & & 24.8 & 3.2 & -30.1 \\
\hline Chugoku & -6.6 & -0.8 & 8.3 & & -0.1 & 5.3 & -19.2 \\
\hline Sikoku & 10.2 & 18.3 & 13.6 & & -1.0 & 23.1 & -43.8 \\
\hline Kyosyu & 14.3 & 13.4 & 3.3 & & -3.5 & 7.6 & -6.5 \\
\hline \multicolumn{8}{|c|}{$1995-1996$} \\
\hline Total & -9.7 & -7.0 & 7.0 & -7.7 & 0.2 & -0.1 & -2.2 \\
\hline Inpatient care & -9.8 & -6.1 & 5.3 & -7.2 & -0.2 & 0.0 & -1.6 \\
\hline Outpatient care & -9.6 & -5.2 & 7.1 & -7.9 & 1.0 & -0.1 & -4.5 \\
\hline \multicolumn{8}{|l|}{ Ownership } \\
\hline National/public & -5.2 & 1.1 & 16.8 & -7.2 & -2.4 & 0.0 & -13.6 \\
\hline Private & -16.8 & -9.9 & 8.7 & -8.1 & 0.7 & 0.4 & -8.5 \\
\hline University & 9.2 & 11.0 & 30.4 & -5.4 & -2.6 & 4.2 & -28.4 \\
\hline Clinic with beds & -8.2 & -3.7 & 10.6 & -8.8 & 2.5 & -1.2 & -7.5 \\
\hline Clinic without beds & -13.8 & -7.2 & 6.3 & -8.6 & 2.2 & -1.5 & -5.0 \\
\hline \multicolumn{8}{|l|}{ Number of beds } \\
\hline 0 & -14.5 & -7.1 & 7.0 & -8.6 & 1.1 & -1.9 & -5.0 \\
\hline$<200$ & -5.9 & -5.9 & 46.8 & -8.7 & 2.3 & -1.8 & -38.6 \\
\hline$>200$ & -3.7 & 2.8 & 6.7 & -7.0 & -4.6 & 4.4 & -6.0 \\
\hline
\end{tabular}


(continued)

\begin{tabular}{|c|c|c|c|c|c|c|c|}
\hline & $\begin{array}{c}\text { Change } \\
\text { in Total } \\
\text { Drug } \\
\text { Costs }\end{array}$ & $\begin{array}{l}\text { Change in } \\
\text { Prescription } \\
\text { Probability }\end{array}$ & $\begin{array}{c}\text { Drug } \\
\text { Switching } \\
\text { Effect }\end{array}$ & $\begin{array}{c}\text { Change } \\
\text { in Drug } \\
\text { Prices }\end{array}$ & $\begin{array}{l}\text { Change } \\
\text { in Daily } \\
\text { Quantity }\end{array}$ & $\begin{array}{l}\text { Change } \\
\text { in Number } \\
\text { of Days } \\
\text { Taken }\end{array}$ & Error \\
\hline \multicolumn{8}{|l|}{$\begin{array}{c}\text { Number of patients } \\
\text { per physician }\end{array}$} \\
\hline$<100$ & -7.3 & -3.2 & 10.8 & -7.4 & -1.4 & 5.6 & -11.7 \\
\hline $100-200$ & -9.5 & -1.2 & 8.8 & -7.7 & 1.1 & -1.0 & -9.5 \\
\hline$>200$ and $<400$ & -9.2 & -4.2 & 6.8 & -8.2 & 2.3 & -0.3 & -5.4 \\
\hline$>400$ & -11.8 & -4.5 & 4.2 & -8.8 & 1.0 & 4.1 & -7.7 \\
\hline \multicolumn{8}{|l|}{ Region } \\
\hline Hokkaido & 0.8 & -0.2 & 15.6 & -8.2 & 2.2 & 2.6 & -11.2 \\
\hline Tohoku & -16.9 & 16.0 & 4.7 & -7.9 & -0.6 & 4.7 & -33.8 \\
\hline Kanto & -2.4 & 27.2 & 18.2 & -7.5 & -0.8 & 4.8 & -44.3 \\
\hline Hokuriku & 5.3 & 461.3 & 9.5 & -8.2 & 1.1 & 3.1 & -461.5 \\
\hline Chubu-Tokai & -16.8 & -7.0 & 2.7 & -8.5 & 0.6 & -0.8 & -3.8 \\
\hline Kinki & -13.2 & -2.3 & 9.1 & -8.0 & -1.1 & 4.0 & -14.8 \\
\hline Chugoku & -5.3 & 3.4 & 5.4 & -7.8 & -1.0 & 0.7 & -6.0 \\
\hline Sikoku & -1.9 & 13.1 & 44.4 & -9.9 & -2.9 & 2.0 & -48.5 \\
\hline Kyusyu & -15.7 & 0.3 & 22.6 & -7.7 & -2.3 & -0.7 & -27.9 \\
\hline
\end{tabular}

Source: Authors' computations based on surveys on drugs (MHW 1994-1996).

Table 9.6

Price Changes and Switching Effects for Selected Drug Groups (\%)

\begin{tabular}{lccrrr}
\hline \multicolumn{5}{c}{ Switching Effect } \\
\hline Three-Digit Group & 1995 Cost Share & 1996 Price Change & 1995 & 1996 & Total \\
\hline 131 & 2.2 & -3.9 & 4.52 & 12.01 & 16.53 \\
214 & 2.8 & -6.7 & 3.56 & 5.95 & 9.51 \\
217 & 3.0 & -7.9 & 5.55 & 9.28 & 14.83 \\
218 & 4.2 & -2.8 & 2.95 & -0.91 & 2.04 \\
219 & 3.4 & -8.8 & 5.55 & 10.54 & 16.09 \\
232 & 4.0 & -9.4 & 5.22 & 2.52 & 7.74 \\
264 & 4.6 & -11.7 & 1.94 & 2.93 & 4.87 \\
422 & 3.7 & -5.6 & -1.19 & 5.79 & 4.6 \\
613 & 7.6 & -11.4 & -0.14 & 9.64 & 9.5 \\
721 & 3.5 & -11.7 & 14.96 & -7.04 & 7.92 \\
Total & 38.83 & -3.30 & 1.44 & 1.93 & 3.40 \\
\hline
\end{tabular}

Source: Authors' computations based on surveys on drugs (MHW 1994-1996).

up by 3.4 percent. The relative magnitudes of the price changes and the switching effects vary widely across drug groups, but in the aggregate they are almost equal.

Observations. We offer the following conjectures based on these three years of data: 
1. The drug-switching effects work to increase the cost of drugs at an annual rate of somewhere between 5 percent and 7 percent.

2. When there is no reduction in drug prices, the trend toward more prescriptions pushes up total drug costs by nearly 2 percent, but when drug prices are reduced, the trend is reversed and prescription probabilities contribute to a 7 percent decline in drug costs.

3. During the 1994-1996 period, the reduction in drug prices and prescription probability together barely offset the drug-switching effect.

\subsection{Economic Incentives in Drug Choice}

Many physicians strongly deny that their drug choices are affected in any way by economic incentives. Are their decisions purely based on medicine and truly free from economics? In this section we examine physician selection behavior using a formal model to analyze a comprehensive dataset on drugs chosen by physicians.

\subsubsection{Selection Functions}

Assume that a physician selects a drug out of $J$ possible drugs using the following selection function:

$$
u_{i k}=\beta_{k}^{\prime} \mathbf{x}_{i}+\gamma_{k}^{\prime} \mathbf{z}_{k}+\varepsilon_{i k},
$$

where $\mathbf{x}$ is a vector of patient and provider characteristics, $\mathbf{z}$ is a vector of drug characteristics, and $\varepsilon$ is the error term. The drug's profit margin is included as one of the elements of $\mathbf{z}$, and the corresponding coefficient in $\gamma$ gives the direction and size of the influence of the profit margin on the physician's selection. The physician selects $\operatorname{drug} j$ for patient $i$ if and only if

$$
u_{i j} \geq u_{i k}, k=1, \ldots, J .
$$

If the error terms $\varepsilon_{i k}$ is independently and identically distributed as an extreme value, ${ }^{5}$ then

$$
\operatorname{Prob}\left(y_{i}=j\right)=\frac{e^{\beta_{j} x_{i}+\gamma_{j} z_{j}}}{\sum_{k=1}^{J} e^{\beta_{k} x_{i}+\gamma_{k}^{\prime} z_{k}}},
$$

where $y_{i}$ is the drug selected by the physician. By fitting a multinomial logit model we obtain estimates of the parameters of the criterion function.

As usual, because the choice model is estimated using data from patients who were given at least one of the $J$ possible drugs, only $J-1$ criterion functions can be estimated and only the differences in coefficients between the $J-1$ drugs and the base drug can be determined. 


\subsubsection{Data and Empirical Strategy}

The MHW collects data for the Survey of Drugs from the same source used to compile the Survey on Socialized Medicine: reimbursement claims submitted by clinics and hospitals. The drug data contain drug identification codes, quantities prescribed, and the cost of drugs to individual patients. We have limited access to the 1994, 1995, and 1996 Surveys of Drugs (MHW). The limitation is that the drug data contain only partial identification codes. The full drug identification code consists of twelve alphanumeric characters, of which we have access to only the first four. The first (and broadest) classification category uses the first three digits, and the second category uses the first four digits. If the price of a particular drug is unique within its four-digit group, we can identify the drug using its quantity and cost information, but if there are two or more drugs that have an identical list price, exact identification of individual drugs is impossible. A data set on individual drug names and full chemical components has been purchased separately from a commercial source for 1995, and additional codes for the other years have been added manually.

In the drug data, each observation contains provider characteristics, patient characteristics (including sex, age bracket, and major disease), and drug characteristics (including estimated out-of-pocket cost, profit margin, and four-digit grouping). There are typically a large number of drugs classified in any four-digit group, and several four-digit groups are contained in each three-digit group (table 9.7). ${ }^{6}$ Thus, some aggregation of individual drugs is inevitable.

Using data on patients who were prescribed any drug in a given threedigit group, we estimate two specifications of our multinomial logit model. In the first model, we use the four-digit groups as our dependent variable. The different drugs within a four-digit group provide variation in profit margins and out-of-pocket costs. Thus, in this model, a particular fourdigit group may become a physician's favorite because it contains a very profitable drug. Whenever possible, we select the first four-digit group in a three-digit group as the base case because it usually has the smallest total drug costs of the four-digit groups.

In the second model, we use the quintiles of drug prices in a given threedigit group as our dependent variable. In addition to individual characteristics, provider characteristics, profit margins, and out-of-pocket costs, dummy variables for each of the four-digit groups are included as independent variables. Thus, this model tries to explain why expensive drugs

6. Our data set contains nine three-digit groups, twenty-nine four-digit groups, and 729 different drugs with a sufficient number of observations for fitting the selection models. See table 9.7 for details. 







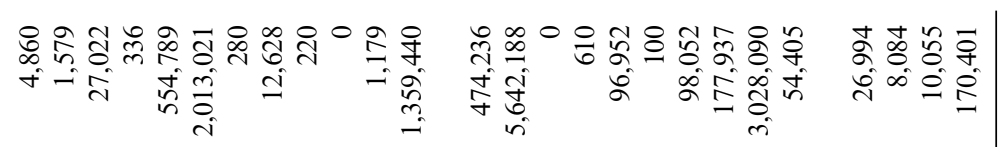

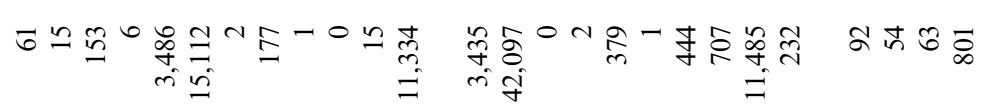

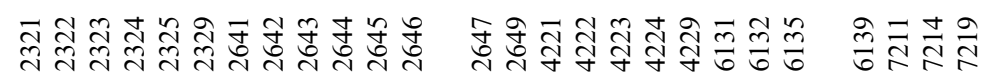

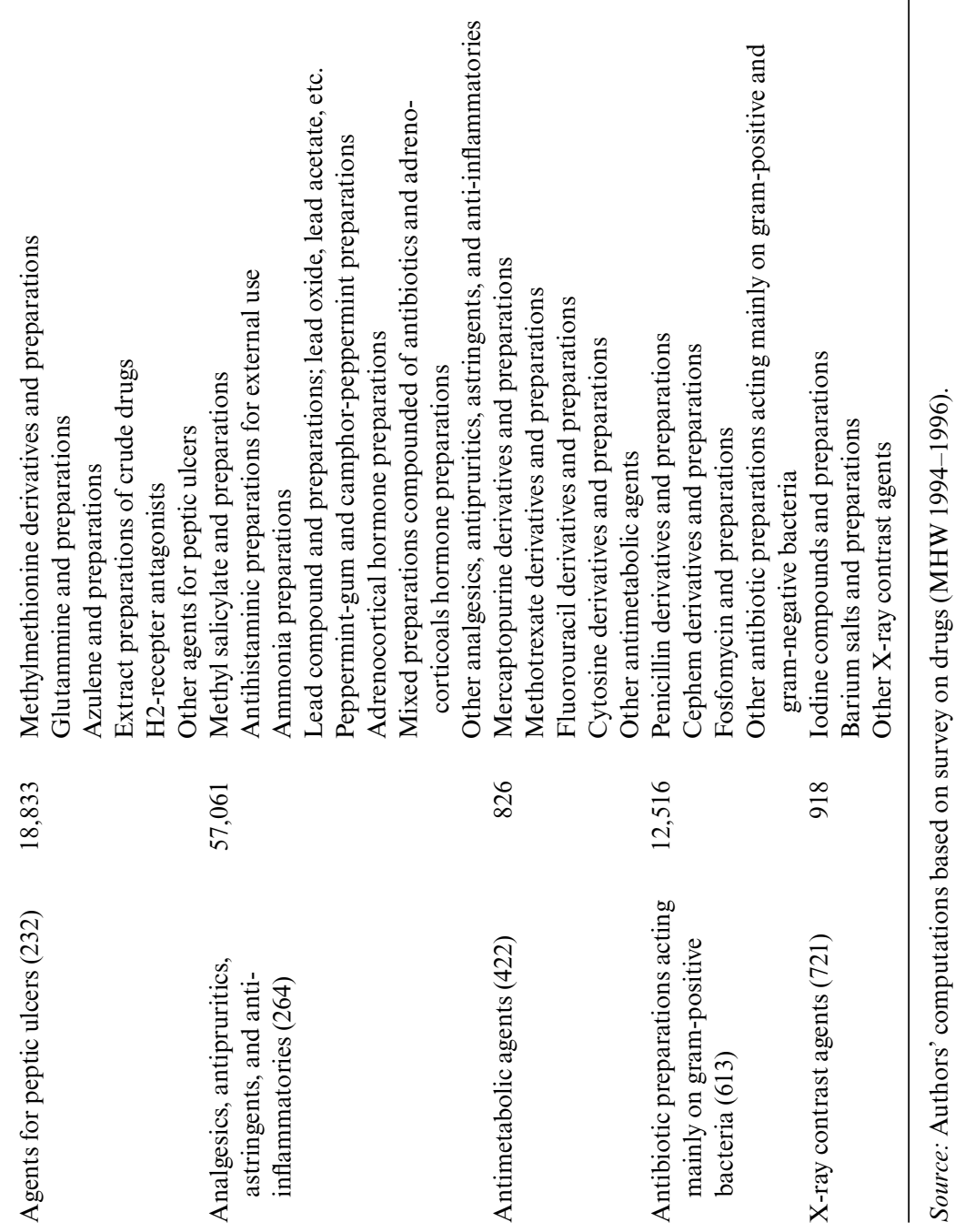


are chosen: Is it because of patient characteristics, provider characteristics, drug characteristics, or economic incentives? In order to maintain consistency with the first model, the base case has been set at the 1st quintile whenever possible.

One possible criticism of these estimations is that there is a considerable degree of arbitrariness in the Japanese pharmaceutical classification system. For example, within any three-digit group there is a large number of drugs whose fourth digits are nine, which denotes all "other agents" in the group. Typically these are drugs that could not be grouped with existing drugs when they were introduced. As a result, many of the most popular drugs in a group often belong to the "nine" category, although they may not be similar at all. Thus, the dummy variables for the four-digit groups may not be reliable, and we may be able to improve our estimation by using better drug classification systems in the selection function.

Fortunately, in an attempt to test the feasibility of a reference price system for Japan, a working group of MHW, consisting mainly of physicians and pharmacologists, has constructed more homogeneous groups of drugs for four categories: (a) peptic ulcers, (b) antihypertensives, (c) analgesics and others, and (d) antibiotics and others. In order to move from the official classification to these reference groups, we need to identify all drugs in a given group. We were unable to do this for (a), (b), and (c). However, we were able to identify most of the individual drugs in group (d) using price differences. Our data regarding the new homogeneous groupings within (d) are summarized in table 9.8. Since the first two groups have fewer than several hundred observations, we do not try to estimate their selection functions separately. We only estimate functions for the last three groups and for the antibiotic drugs group as a whole.

\subsubsection{Results}

\section{First Model}

Judging from the pseudo- $R^{2}$ values, the estimated model fits the data very well, with most of the explanatory power provided by the profit margin variable. Of the twenty four-digit group selection functions, this variable was significant in nineteen. An example of the estimated selection function is shown for antihypertensives in table 9.9. The sizes of the coefficients are not intuitive, however, because of the comparative or conditional nature of the estimated selection functions.

To interpret the estimated profit margin coefficients, we perform a simulation in which all profit margins are set equal to zero without changing prices. The result of the simulation is summarized in table 9.10. Although the results vary from one three-digit group to another, in two of the groups the reduction in total drug costs exceeds 30 percent. In three additional groups this reduction exceeds 20 percent, and in two other groups it ex- 


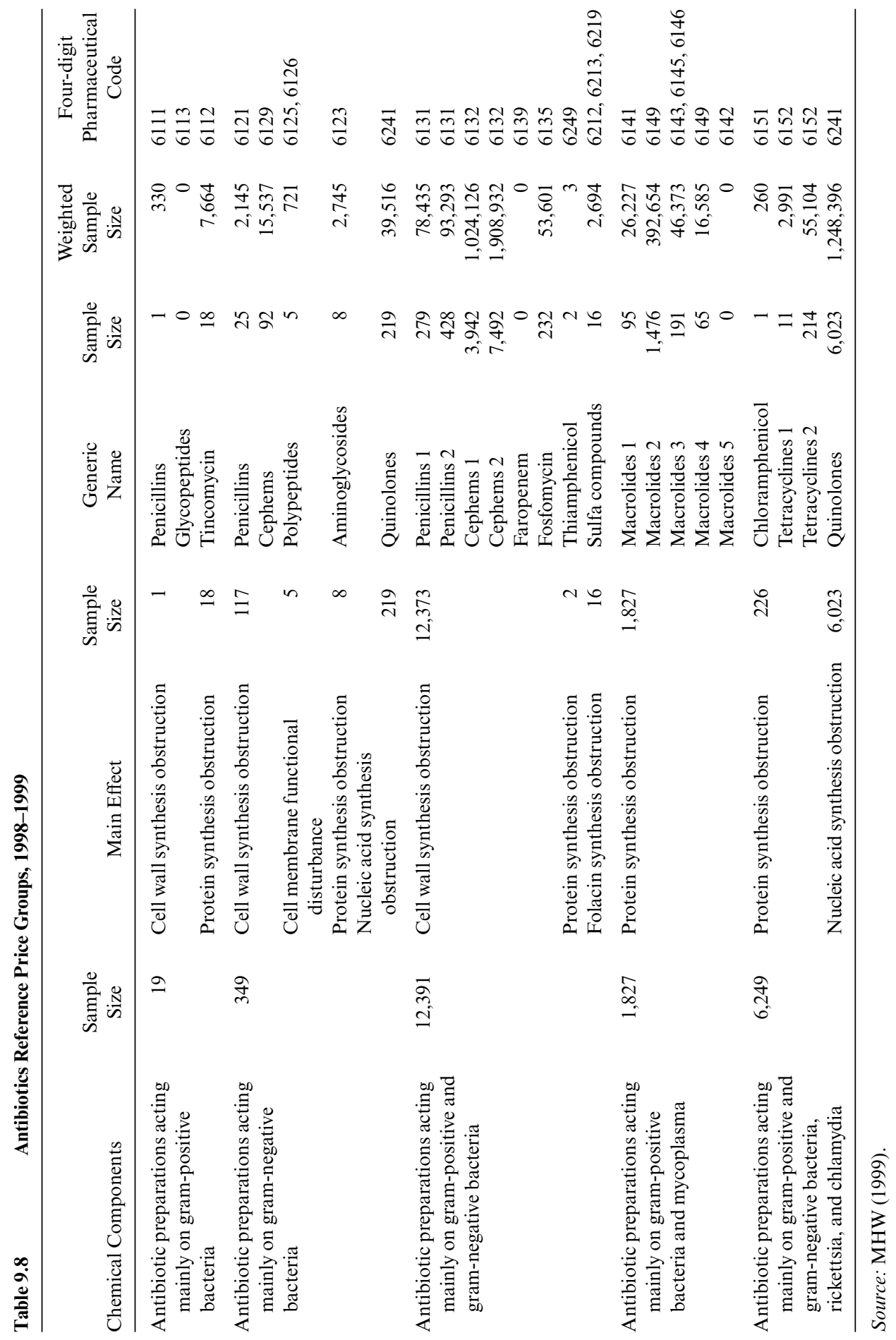


Table 9.9

Selection Function for Antihypertensives, Model 1

(multinomial regression)

\begin{tabular}{|c|c|c|c|c|}
\hline \multirow[b]{2}{*}{ Variable } & \multicolumn{2}{|c|}{ Group 2144} & \multicolumn{2}{|c|}{ Group 2149} \\
\hline & Coefficient & $z$ & Coefficient & $z$ \\
\hline Profit margin & 0.266 & 223.058 & 0.220 & 186.088 \\
\hline Out-of-pocket costs & 0.004 & 3.851 & 0.010 & 8.927 \\
\hline Number of beds & 0.000 & 8.800 & 0.000 & 7.598 \\
\hline Female & -0.218 & -18.495 & -0.171 & -14.843 \\
\hline Age 0-19 & 13.699 & 0.083 & 14.766 & 0.090 \\
\hline Age 20-39 & -0.440 & -9.121 & -0.677 & -14.804 \\
\hline Age $40-59$ & 0.112 & 5.989 & 0.301 & 16.380 \\
\hline Age $65-75$ & -0.340 & -17.322 & -0.023 & -1.200 \\
\hline Age $76+$ & -0.207 & -8.170 & 0.045 & 1.811 \\
\hline Circulatory diseases & 0.115 & 9.415 & 0.168 & 14.057 \\
\hline Gm worker & -0.419 & -18.241 & 0.021 & 0.925 \\
\hline Gm dependent & -0.647 & -29.640 & -0.722 & -33.759 \\
\hline Gm elderly & 0.245 & 7.486 & 0.193 & 6.082 \\
\hline Nh elderly & 0.171 & 6.460 & 0.195 & 7.670 \\
\hline National & -0.291 & -17.518 & -0.115 & -7.092 \\
\hline University & 0.760 & 10.237 & 0.955 & 13.025 \\
\hline Clinic with beds & 0.557 & 30.631 & 0.634 & 35.622 \\
\hline Clinic without beds & -0.707 & -45.492 & -0.910 & -59.956 \\
\hline Constant & -1.571 & -62.090 & -0.800 & -32.398 \\
\hline$N$ & $1,214,398$ & & & \\
\hline Log-likelihood & $-883,404.8$ & & & \\
\hline $\operatorname{LR} \chi^{2}(36)$ & $270,078.53$ & & & \\
\hline Prob $>\chi^{2}$ & 0.0000 & & & \\
\hline Pseudo $R^{2}$ & 0.1326 & & & \\
\hline
\end{tabular}

Source: Authors' computations based on surveys on drugs (MHW 1994-1996).

Note: Outcome choice circulatory diseases $=$ a dummy variable for patients with circulatory disease as their primary disease. $\mathrm{Gm}-=$ patients under government managed insurance. Nh$=$ patients under town- or city-managed national health insurance. National $=$ patients of hospitals or clinics run by the Japanese government. University = patients of teaching hospitals.

ceeds 10 percent. Overall, the reduction amounts to almost 20 percent of drug costs.

\section{Second Model}

We estimate the selection functions for all nine groups, but we only report the results for antihypertensives (214; table 9.11). Roughly speaking, in the second model, the physician selects the cost of the drug. This straightforward model makes it very easy to interpret the results. The magnitudes of the coefficients on the profit margin variables are very stable, but their pattern of variation suggests that profit margins are relatively more important in inducing selection of higher-priced drugs. Also, by compar- 







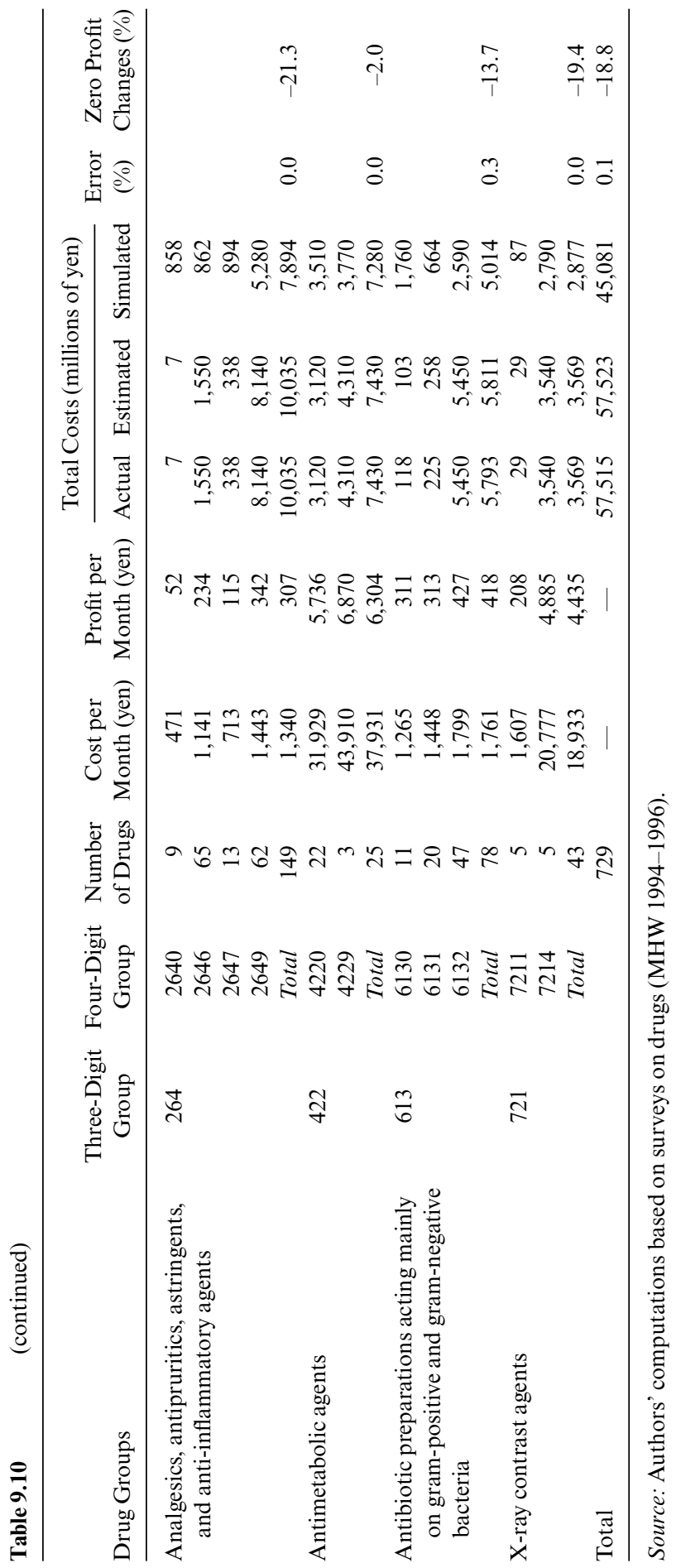




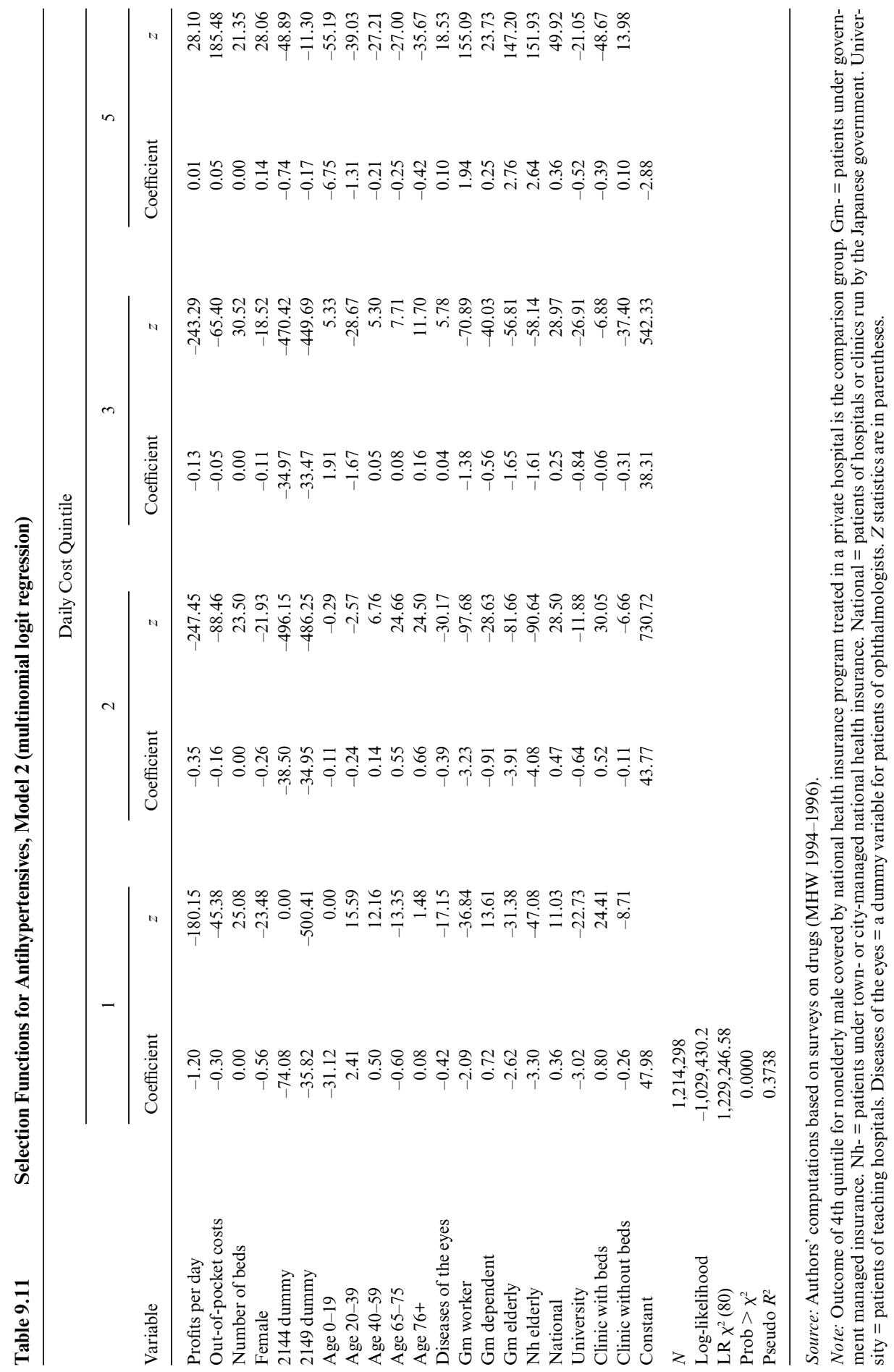


ing the dummy variables ${ }^{7}$ for 2144 and 2149 we see that while 2144 is more popular, 2149 probably does not offer many products in the lower three price zones. Patient characteristics seem to be important in deciding which price zone to select: The elderly seem to be very important in accounting for the highest-priced drugs.

In order to give an idea of the interpretation of the size of the estimated profit margin coefficients, we carry out a simulation identical to that in the first model. The results of the simulation are summarized in table 9.12. In four groups the reduction in total drug costs exceeds 50 percent. In four additional groups this reduction exceeds 30 percent, and in the remaining group it exceeds 4 percent. Overall, the reduction amounts to 45 percent of drug costs.

\section{Using Reference Price Group Information}

Using the framework of the second model and the reference group information of the Working Committee of the MHW in 1998, we estimate selection functions for three individual reference groups and antibiotics (as a whole). Presumably, drugs within reference groups are close substitutes, but there seems to be important heterogeneity among them. For example, we have noticed that in some cases the most expensive drugs are not necessarily the most profitable, even though they are used most frequently and were introduced most recently. One can think of several reasons why this may happen:

1. Newer drugs may be preferred by physicians because they reflect technological innovation and hence are better in some sense, even though they may not be the most profitable drugs in the group.

2. Manufacturers may be more reluctant to offer large discounts for new drugs because doing so will shorten their economic life.

3 . The government may have become more stringent in pricing new drugs in an attempt to control drug costs.

In order to capture these effects we add a new variable indicating the year each drug was introduced. There are two exceptions to this rule: (a) if the drug is a "me-too" drug, we chose the first year the particular chemical was approved; (b) if the drug had already been approved at the beginning of our sample we treat it as having been introduced in $1967 .{ }^{8}$ If physicians prefer drugs that are more profitable, "new," or both, we expect the year variable to work in the same way as the profit margin variable.

Table 9.13 reports the results for the largest group, antibiotic agents for gram-negative and -positive bacteria. The estimation results are fairly con-

7. The base-case four-digit class is 2140 in this case.

8. Nihon-seiyaku-danntai-rengoukai, Hoken-yakka-kenkyu-iinkai (1997) includes data on drugs that were approved after 1967. 


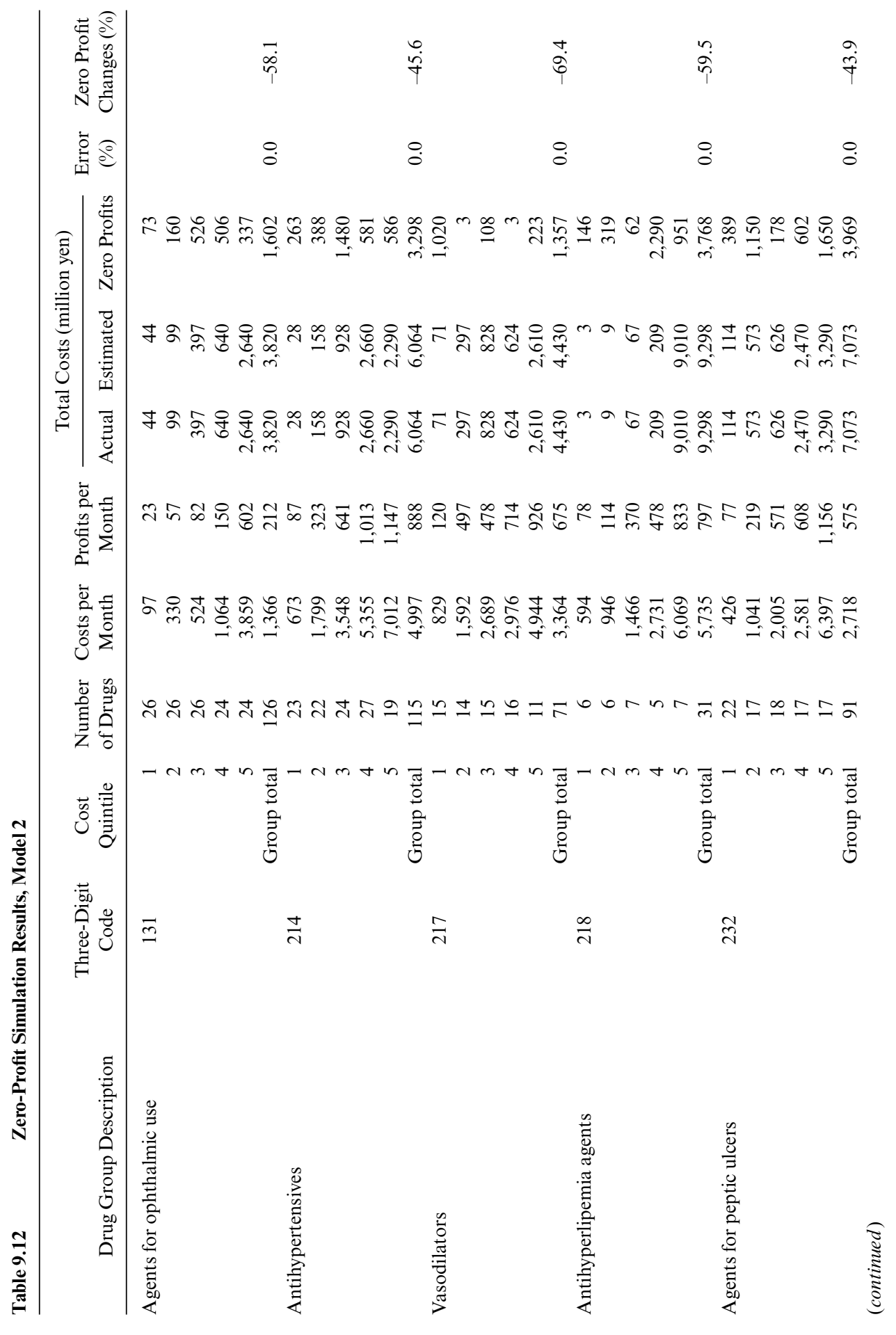




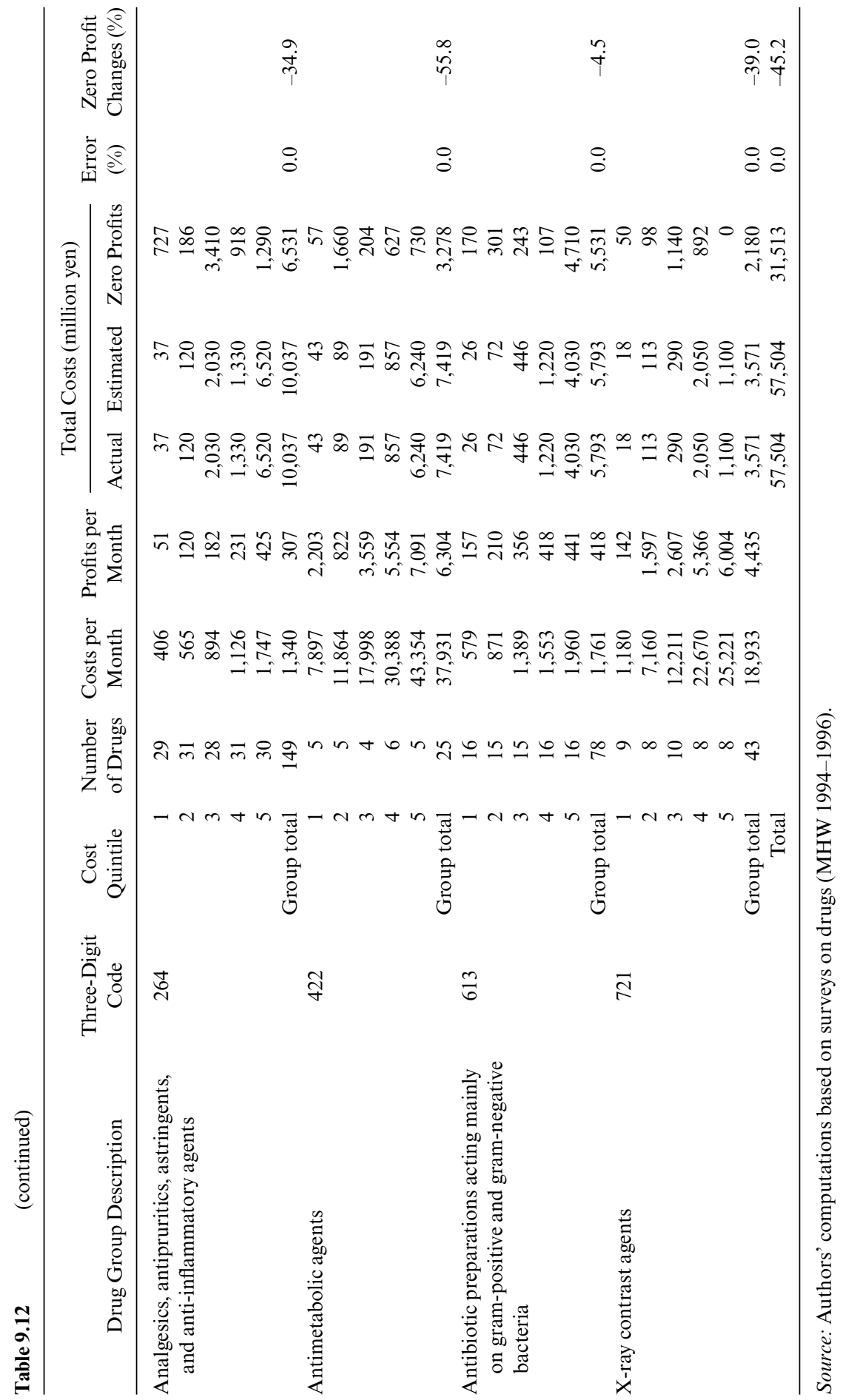




\begin{tabular}{|c|c|c|c|}
\hline Variable & Coefficient & $z$ & Marginal Eft \\
\hline \multicolumn{4}{|c|}{ Quintile 1} \\
\hline Profit margin & -0.16 & -212.57 & -0.16 \\
\hline Year introduced & -0.57 & -155.64 & -0.88 \\
\hline Number of beds & 0.00 & -9.26 & 0.00 \\
\hline Female & -0.85 & -37.84 & -0.95 \\
\hline Age $0-19$ & -2.50 & -46.14 & -3.24 \\
\hline Age $20-39$ & 0.21 & 3.99 & 0.33 \\
\hline Age $40-59$ & -0.96 & -17.19 & -0.95 \\
\hline Age $65-75$ & -2.21 & -27.50 & -2.23 \\
\hline Age $76+$ & -3.29 & -25.35 & -3.41 \\
\hline Circulatory diseases & 1.66 & 30.23 & 1.70 \\
\hline Respiratory diseases & 1.35 & 49.45 & 1.41 \\
\hline Gm worker & 0.41 & 12.70 & 0.28 \\
\hline Gm dependent & -0.54 & -20.11 & -0.62 \\
\hline Gm elderly & 0.23 & 1.71 & 0.22 \\
\hline Nh elderly & 0.90 & 9.88 & 0.95 \\
\hline Public Hospital & 0.04 & 0.61 & 0.02 \\
\hline University & -9.53 & -0.07 & -9.22 \\
\hline Clinic with beds & 0.82 & 16.62 & 0.73 \\
\hline Clinic without beds & 0.53 & 10.84 & 0.42 \\
\hline Constant & 35.71 & 173.81 & \\
\hline \multicolumn{4}{|c|}{ Multinomial logit regression } \\
\hline$N$ & $3,158,387$ & & \\
\hline Log-likelihood & $-1,644,565.5$ & & \\
\hline $\operatorname{LR} \chi^{2}(76)$ & $3,145,966.69$ & & \\
\hline Prob $>\chi^{2}$ & 0.0000 & & \\
\hline \multirow[t]{2}{*}{ Pseudo $R^{2}$} & 0.4889 & & \\
\hline & Quintile 2 & & \\
\hline Profit margin & -0.10 & -345.91 & -0.10 \\
\hline Year introduced & -0.22 & -152.29 & -0.52 \\
\hline Number of beds & -0.01 & -44.42 & -0.01 \\
\hline Female & 0.05 & 4.93 & -0.04 \\
\hline Age $0-19$ & 0.63 & 23.26 & -0.11 \\
\hline Age $20-39$ & 0.84 & 30.62 & 0.97 \\
\hline Age $40-59$ & -0.63 & -20.36 & -0.61 \\
\hline Age $65-75$ & -1.45 & -35.47 & -1.47 \\
\hline Age $76+$ & -1.27 & -22.42 & -1.39 \\
\hline Circulatory diseases & 1.35 & 52.05 & 1.39 \\
\hline Respiratory diseases & 0.76 & 58.66 & 0.82 \\
\hline Gm worker & -0.18 & -10.78 & -0.31 \\
\hline Gm dependent & -0.65 & -51.95 & -0.73 \\
\hline Gm elderly & 0.36 & 6.19 & 0.35 \\
\hline Nh elderly & 0.83 & 18.49 & 0.89 \\
\hline Public Hospital & 0.27 & 10.31 & 0.26 \\
\hline University & -11.64 & -0.07 & -11.33 \\
\hline Clinic with beds & 0.25 & 8.91 & 0.15 \\
\hline Clinic without beds & 0.27 & 9.65 & 0.16 \\
\hline Constant & 15.44 & 171.22 & \\
\hline
\end{tabular}

(continued) 
Table 9.13 (continued)

\begin{tabular}{|c|c|c|c|}
\hline Variable & Coefficient & $z$ & Marginal Effect \\
\hline \multicolumn{4}{|c|}{ Quintile 3} \\
\hline Profit margin & -0.02 & -169.93 & -0.02 \\
\hline Year introduced & 0.11 & 134.24 & -0.19 \\
\hline Number of beds & 0.00 & -20.65 & 0.00 \\
\hline Female & -0.15 & -28.11 & -0.24 \\
\hline Age $0-19$ & 2.06 & 126.79 & 1.32 \\
\hline Age 20-39 & 0.42 & 24.24 & 0.55 \\
\hline Age 40-59 & 0.24 & 13.29 & 0.25 \\
\hline Age $65-75$ & -0.04 & -1.73 & -0.06 \\
\hline Age 76+ & 0.26 & 8.05 & 0.14 \\
\hline Circulatory diseases & 0.20 & 14.34 & 0.24 \\
\hline Respiratory diseases & 0.06 & 8.93 & 0.11 \\
\hline Gm worker & -0.04 & -3.83 & -0.17 \\
\hline Gm dependent & -0.02 & -4.01 & -0.10 \\
\hline Gm elderly & 0.06 & 1.72 & 0.06 \\
\hline Nh elderly & 0.33 & 12.85 & 0.38 \\
\hline Public Hospital & 0.19 & 14.38 & 0.18 \\
\hline University & -0.87 & -10.09 & -0.56 \\
\hline Clinic with beds & 1.07 & 84.55 & 0.98 \\
\hline Clinic without beds & 0.73 & 58.77 & 0.63 \\
\hline Constant & -8.70 & -160.91 & \\
\hline \multicolumn{4}{|c|}{ Quintile 4} \\
\hline Profit margin & n.a. & 0.00 & \\
\hline Year introduced & n.a. & -0.30 & \\
\hline Number of beds & n.a. & 0.00 & \\
\hline Female & n.a. & -0.10 & \\
\hline Age $0-19$ & n.a. & -0.74 & \\
\hline Age $20-39$ & n.a. & 0.12 & \\
\hline Age $40-59$ & n.a. & 0.01 & \\
\hline Age $65-75$ & n.a. & -0.02 & \\
\hline Age $76+$ & n.a. & -0.12 & \\
\hline Circulatory diseases & n.a. & 0.04 & \\
\hline Respiratory diseases & n.a. & 0.05 & \\
\hline Gm worker & n.a. & -0.13 & \\
\hline Gm dependent & n.a. & -0.08 & \\
\hline Gm elderly & n.a. & -0.01 & \\
\hline Nh elderly & n.a. & 0.05 & \\
\hline Public Hospital & n.a. & -0.01 & \\
\hline University & n.a. & 0.31 & \\
\hline Clinic with beds & n.a. & -0.09 & \\
\hline Clinic without beds & n.a. & -0.11 & \\
\hline Constant & n.a. & & \\
\hline
\end{tabular}

sistent with those from the other three groups. Larger profit margins and later introduction years increase the selection of more expensive drugs. The sensitivity is larger for more expensive drugs. In other words, physicians can be very easily persuaded to choose more expensive drugs if either their profit margins are larger or they are newer. They can also be very eas- 
Table 9.13 (continued)

\begin{tabular}{lcrr}
\hline Variable & Coefficient & \multicolumn{1}{c}{$z$} & Marginal Effect \\
\hline & Quintile 5 & & \\
Profit margin & 0.00 & 55.15 & 0.00 \\
Year introduced & 0.74 & 870.17 & 0.44 \\
Number of beds & 0.00 & 23.74 & 0.00 \\
Female & 0.27 & 68.52 & 0.17 \\
Age 0-19 & 1.46 & 175.51 & 0.72 \\
Age 20-39 & -0.40 & -47.88 & -0.27 \\
Age 40-59 & -0.08 & -9.66 & -0.07 \\
Age 65-75 & 0.06 & 5.18 & 0.04 \\
Age 76+ & 0.25 & 15.67 & 0.13 \\
Circulatory diseases & -0.14 & -17.27 & -0.10 \\
Respiratory diseases & -0.15 & -33.27 & -0.10 \\
Gm worker & 0.34 & 59.08 & 0.21 \\
Gm dependent & 0.21 & 41.95 & 0.13 \\
Gm elderly & 0.01 & 0.34 & 0.00 \\
Nh elderly & -0.20 & -16.24 & -0.15 \\
Public Hospital & -0.01 & -0.75 & -0.02 \\
University & -0.58 & -24.35 & -0.27 \\
Clinic with beds & 0.02 & 3.23 & -0.07 \\
Clinic without beds & 0.12 & 20.42 & 0.02 \\
Constant & -46.97 & -824.83 & \\
\hline
\end{tabular}

Source: Authors' computations based on surveys on drugs (MHW 1994-1996).

Note: Outcome of 4th quintile for nonelderly male covered by a national health insurance program treated in a private hospital is the comparison group. "Gm" stands for a person covered by health insurance managed by government. "Nh" stands for a person covered by a national health insurance program. N.a. = not applicable.

ily persuaded not to use the least expensive drugs if either their profit margins are smaller or they are older. For antibiotic drugs as a whole the same tendencies are confirmed, but much more emphasis seems to be placed on recent introduction, particularly for the most expensive drugs.

Again, we have carried out simulations for the zero profit-margin case (table 9.14). For the first group, the reduction in total costs is about 30 percent. For the second group, this reduction is about 20 percent, and for the third group, it is computed to reach close to 70 percent, although this figure may be unrealistic.

\subsection{Inefficiencies in the Japanese Drug Price System}

\subsubsection{Inefficiency in the Production of Health Care Services}

Under the present drug-pricing policy, providers of health care services are subject to strong economic incentives to prescribe as many drugs as possible to their patients. The wrong economic incentives can distort providers' decisions in two ways. First, they may influence the physician's se- 


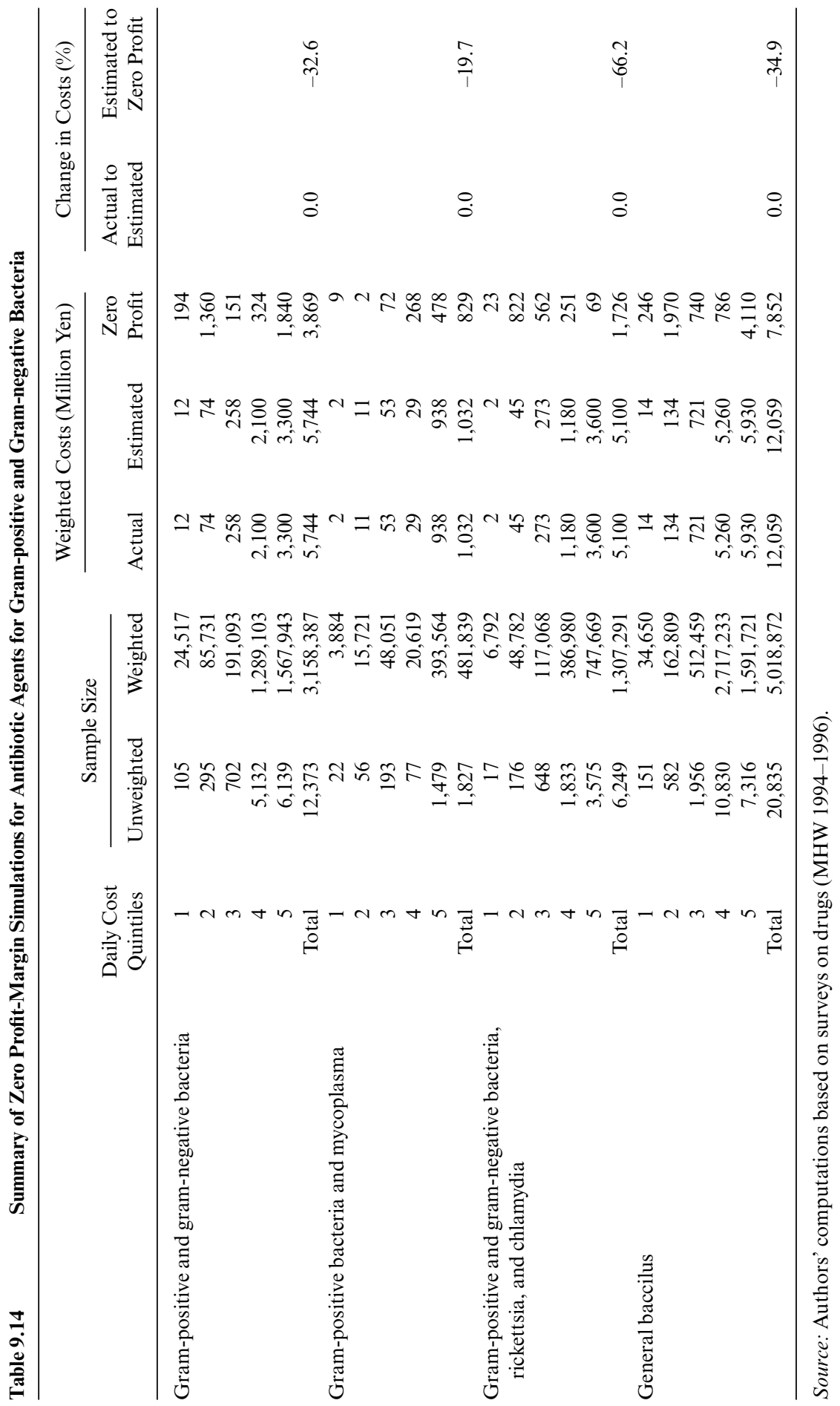


lection decision among competing drugs, and second, they may influence the physician's selection decision between drugs and other factors of production, including physician services:

1. If providers are to produce their services efficiently, they must select the least-cost combination of production factors from all feasible combinations of inputs. If drug $A$ and $\operatorname{drug} B$ have identical chemical compositions, the efficient provider must choose the one that costs less. But a system that gives differential profit margins across drugs tends to drive providers toward using the drug with the highest profit margin. This is usually the drug with the higher price. We have shown that this inefficiency can amount to as much as 30 percent of total expenditures on drugs.

2. In many realistic cases, moreover, there is a certain degree of substitutability between drugs and physicians' time (counseling). Under the present medical pricing system, in which physicians' time is not adequately reimbursed and profit margins are provided for drugs, it is certain that drugs are selected over other time-intensive procedures.

\subsubsection{Substitution of New Drugs}

If drug discounts had remained within the reasonable zones, drug prices could not have been continuously lowered throughout the 1990s. This is evidence that competition for larger shares among drug companies has been very effective in driving down prices. We should, however, also note that large numbers of drugs have been introduced simultaneously. In fact, as we have seen in the decomposition analysis, the drug companies seem to have been able to offset reductions in prices of existing drugs by introducing new drugs and setting their prices sufficiently high.

The introduction of new drugs, however, came at a cost. The drug companies have been engaged in some of the most intensive research and development activity in Japan's major industries. In 1995, for example, the industry spent 640 billion yen out of sales of 8 trillion yen, or 8 percent, on research and development (R\&D). In contrast, one of the most competitive industries in Japan, the electronics and communications industry, spent only 5 percent of sales on $R \& D$ (figure 9.1). Such an intensive $R \& D$ effort in our drug industry may have been encouraged by several factors: (a) The costs of R\&D for new drugs are taken into account when the government sets the reimbursement price for the first time; (b) high prices make it possible for firms to offer discounts to providers, thereby rapidly expanding sales and profitability; and (c) without new drugs, firms' profitability declines continuously as the prices of existing drugs are repeatedly cut by the government.

\subsubsection{Dynamic Inefficiency}

The Japanese drug industry, with the second largest domestic market in the world, has enjoyed very high profitability (figure 9.2). It is supported by 


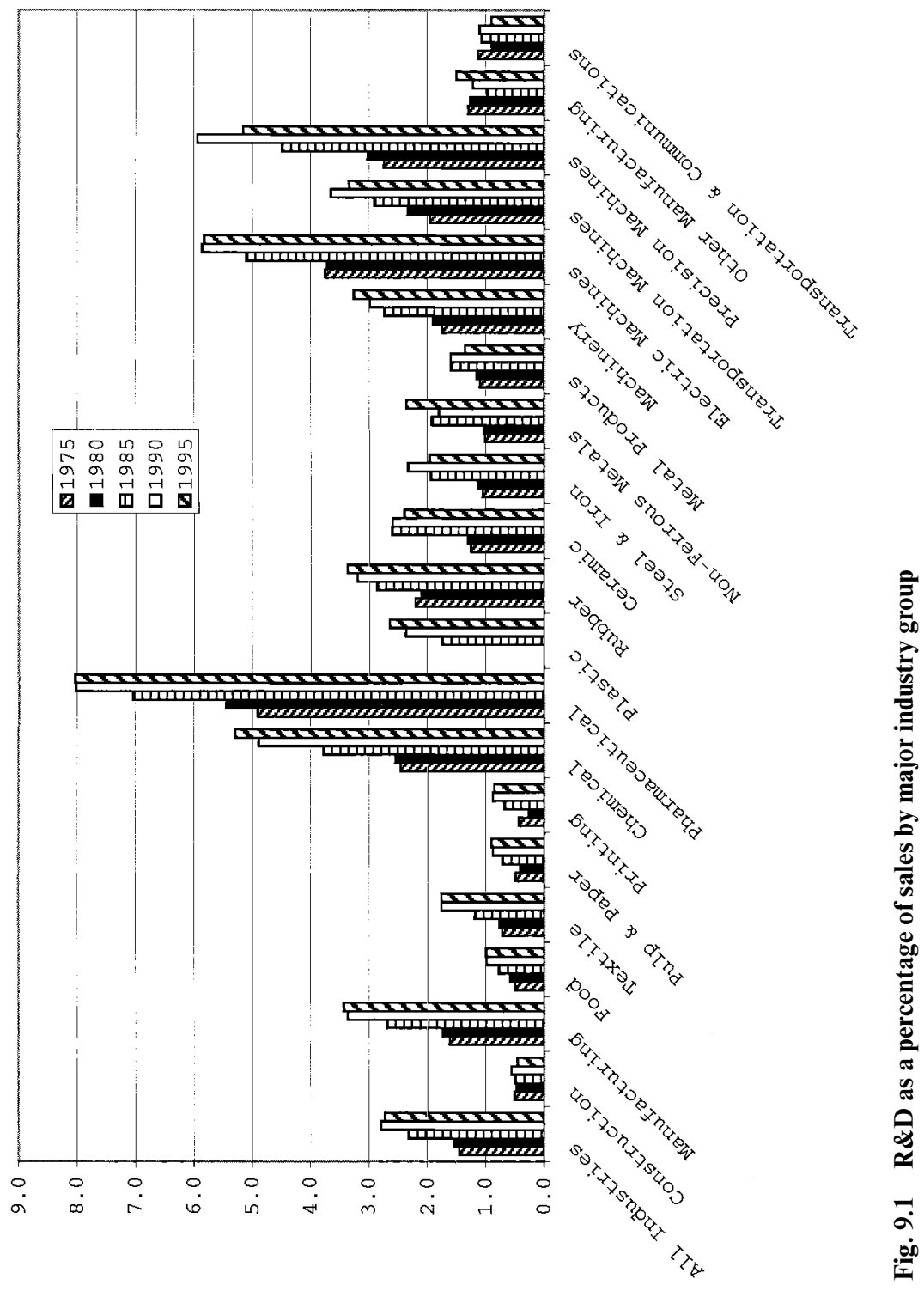




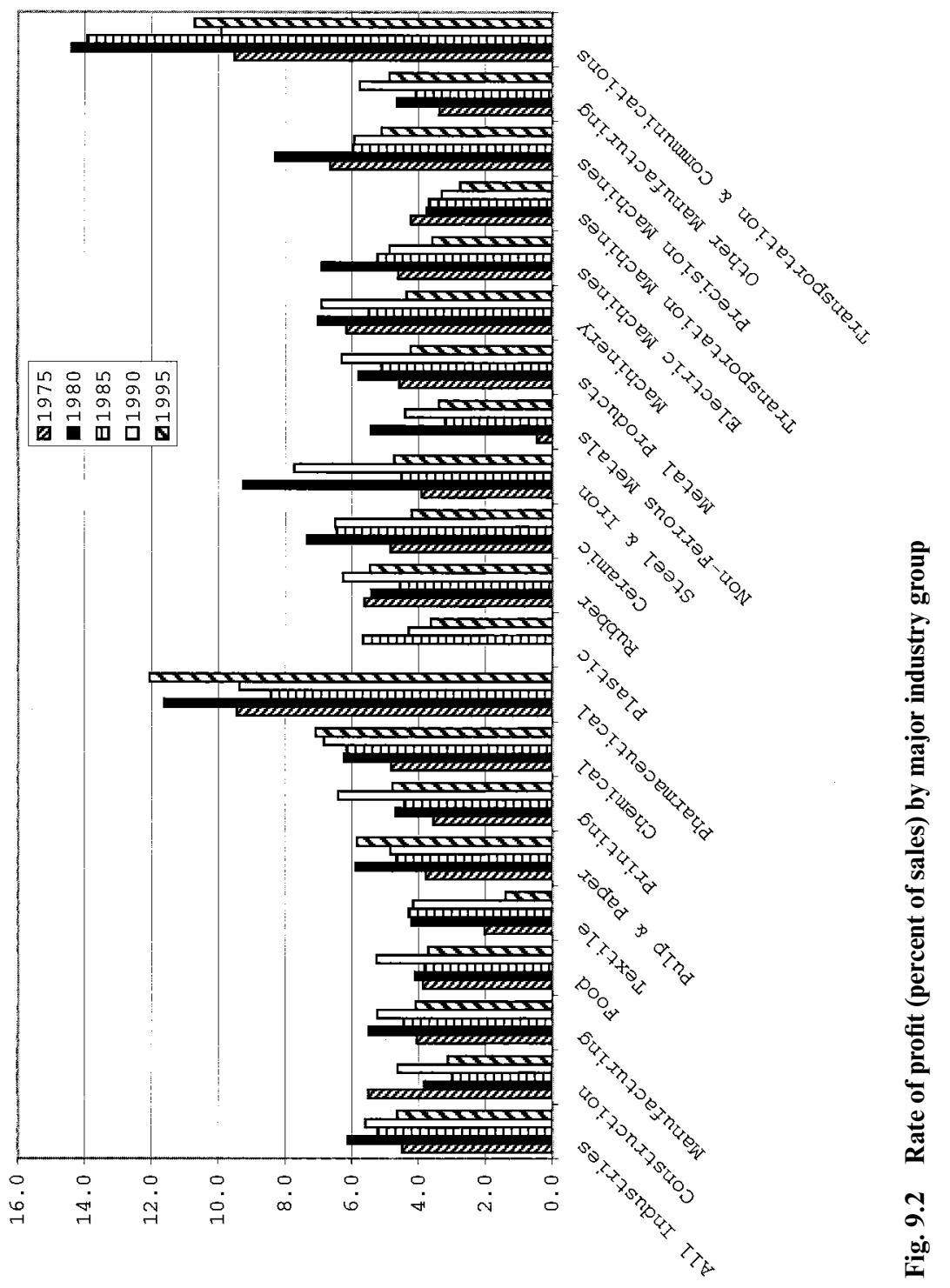


Table 9.15

Japanese Drug Imports and Exports (Billion Yen)

\begin{tabular}{ccccccc}
\hline & Production & $\begin{array}{c}\text { All } \\
\text { Exports }\end{array}$ & $\begin{array}{c}\text { Exports } \\
\text { Asia }\end{array}$ & $\begin{array}{c}\text { All } \\
\text { Imports }\end{array}$ & $\begin{array}{c}\text { Imports from the } \\
\text { United States }\end{array}$ & $\begin{array}{c}\text { Imports from } \\
\text { Europe }\end{array}$ \\
\hline 1985 & 4,001 & 30 & 18 & 308 & 129 & 162 \\
1986 & 4,280 & 30 & 19 & 330 & 122 & 193 \\
1987 & 4,825 & 30 & 19 & 355 & 117 & 225 \\
1988 & 5,059 & 28 & 21 & 376 & 118 & 242 \\
1989 & 5,502 & 27 & 19 & 417 & 123 & 322 \\
1990 & 5,595 & 36 & 18 & 469 & 133 & 343 \\
1991 & 5,697 & 42 & 24 & 485 & 129 & 433 \\
1992 & 5,574 & 49 & 26 & 588 & 129 & 430 \\
1993 & 5,695 & 44 & 23 & 584 & 131 & \\
\hline
\end{tabular}

Source: MHW (1999), Yearbook of Production Statistics for the Pharmaceutical Industry 1999

the highest R\&D rates among Japan's major industries. The story, however, may not lead to such a happy ending if one looks into the industry more closely. In fact, it is possible that these impressive R\&D expenditures may have actually weakened the industry rather than strengthening it. To the extent that they were induced by regulation, these $R \& D$ expenditures are simply the costs of operating under this unproductive regulation.

The statistics on the international drug trade are our first clue that there is something very strange about the industry. According to MHW statistics, drug exports amount to less than one-tenth of drug imports. Furthermore, in terms of the regional pattern of trade, almost half of the exports go to countries in Asia, whereas most of the imports are from the United States and Europe (table 9.15). This indicates the presence of substantial technological gaps among these regions, with Japan in a middle position. An analysis of drug patent data from the world's 150 largest companies (Anegawa 1996) reaches a similar conclusion: 53 percent of the world's technological capital is found in the United States, 36.6 percent in Europe, and only 10.1 percent in Japan. These findings are consistent with the hypothesis that Japanese drug price controls have generated excess returns to "new" drugs, which are similar to existing drugs, or "me-too" drugs. Most of the R\&D expenditure has been allocated to copycat development rather than to truly innovative drugs.

By its nature, investment in innovative drugs involves higher risk, and under the Japanese regulatory scheme, the lower-risk investment into developing "me-too" drugs has proved just as profitable. It is not surprising that one finds that most of the R\&D funds of Japanese drug firms are allocated to these easier alternatives. The process of approving and pricing "new" drugs has long been notorious for its disregard of public accountability, scientific objectivity, and global standards. ${ }^{9}$ In fact, there are a large

9. A new process, called good clinical practice (GCP), was adopted in 1998 as a result of foreign pressure. 


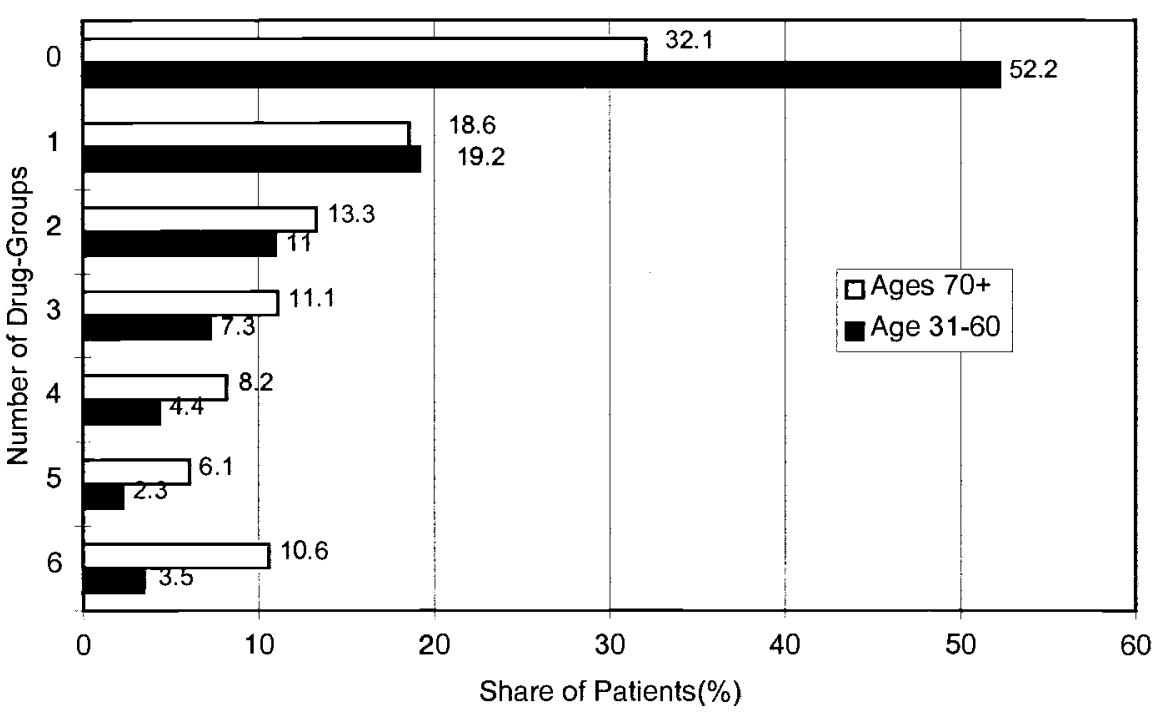

Fig. 9.3 Distribution of the number of drug groups given to outpatients with circulatory diseases

Source: Survey on Socialized Medicine (MHW 1994-1996).

number of drugs that are widely used in Japan but are not approved in the United States or Europe because their producers cannot offer sufficient evidence of increased effectiveness and superiority over existing drugs. ${ }^{10}$

\subsubsection{External Diseconomies: Excessive Usage}

The wrong economic incentives for the use of drugs may be generating very serious external diseconomies. Elderly patients are prescribed a particularly large number of drugs under the present system. According to the Survey on Socialized Medicine (MHW 1994-1996), the cost of drugs and injections for an elderly outpatient was 905 points $^{11}$ in 1996, almost twice the 477 points for the rest of the population. Using the new drug data compiled by the government, ${ }^{12}$ we examine drug consumption more closely by selecting patients with circulatory diseases, the most prevalent diseases among the elderly.

Figure 9.3 illustrates that 25 percent of patients aged seventy and up received four or more groups of drugs, compared with 10.2 percent of patients aged thirty-one to sixty. Likewise, 10.6 percent of patients aged seventy and up consumed more than six groups of medicine. The risk of side effects tends to increase exponentially with the number of drugs consumed, and this is particularly acute among elderly patients with diminished liver

10. Recently, however, the MHW has changed its policy and started to remove some drugs widely used for cerebrovascular diseases due to lack of clinical effectiveness.

11. A point is 10 yen in government reimbursement schedule.

12. The drug data set is explained in detail in section 9.3.2. 
and kidney functions. Moreover, many elderly patients utilize multiple providers, so the risks due to consumption of large numbers of drugs are neither controlled nor managed.

A somewhat separate issue exists with antibiotics. The distribution of antibiotics used in Japanese hospitals is concentrated very heavily among the latest generation of drugs, whereas other major countries continue to use older-generation drugs. In fact, it is not unusual to find new antibiotics being given to patients in outpatient settings with such mild afflictions as a common cold, a practice that runs a high risk of creating drug-resistant bacteria strains. This is another external diseconomy created by a regulatory system that deprives health care providers of the incentive to use less expensive, but still effective, existing drugs.

\subsection{Various Reform Proposals}

In view of the serious distortions created by the present drug-pricing policy, it is not surprising that a number of reform proposals have been advocated in the past three years. We review the merits and demerits of these proposals as reported by a government commission in January 1998.

\subsubsection{Reimbursement of Actual Drug Costs (Liberal Democrats)}

A body of ruling parties, including the Liberal Democrats, argue that the government should abandon drug price regulation altogether and move toward reimbursing providers the purchase costs of the drugs. The government commission objects to this plan on several grounds. First, patients will be charged differently from one provider to another. Second, patients will shop for better prices and choose large hospitals to get lower costs of drugs. Third, administrative costs will be huge for both insurers and providers. Fourth, providers may engage in such rent-seeking activities as utilizing extra middlemen to increase drug costs. The commission concludes that this plan should be modified at least to the extent that only the lesser of actual costs and list price is reimbursed.

\subsubsection{Insurers Acting as Purchasing Agents}

The second proposal the commission examined advocates a system in which drugs are purchased by insurers and supplied to providers as they are dispensed to their patients. Prices would be negotiated between manufacturers and insurers in the market. The commission asserts that although profit margins will vanish completely in this system, two problems will result: (a) Providers will have strong incentives to give excessive amounts of drugs to patients, as they lose track of drug costs; and (b) providers will have no incentive to use less expensive drugs. A variation on this was advocated by the Japan Medical Association (JMA) in a last-minute effort to abort the reference price system MHW was about to introduce. The JMA 
asked the government to purchase all drugs that providers need for patients with public health insurance.

\subsubsection{Reference Price System of the MHW}

Finding the other alternatives unacceptable, the commission considered the reference price system. In this system, first drug manufacturers announce list prices, and then the government sets a single reimbursement price for all drugs in a given homogeneous group. The reimbursement price would be set equal to a weighted average of the list prices in each group. The majority of commission members found this system to be the most desirable system, because it promotes price competition among substitutable drugs and allows manufacturers to price their own products. The member of the commission who represents JMA, however, opposed this plan strongly, presumably because JMA members would lose tremendous income by moving to this system. The JMA would agree to move to a different system only if it is allowed to recover its losses elsewhere in the fee schedule. Drug companies, particularly powerful drug companies, were not happy either. They feared that patients would not be willing to bear additional costs if they priced their products above the reimbursement prices, so they would lose part of their premium on higher-quality products. They also feared that the system would be open to considerable intervention by the MHW, as it depends critically on how broadly or how narrowly each reference group is defined. In view of this strong opposition, the ruling parties decided to mothball the plan just prior to the formation of the fiscal year (FY) 1999 government budget plan.

\subsubsection{Removing Drug Costs from Public Health Insurance}

Although no one has advocated this option so far, it is a logical alternative, given that the government will continue to regulate drug prices in one way or another as long as drugs are covered by public health insurance. It is hard to imagine, however, that a majority of Japanese will want to remove drug costs completely from the provisions of public health insurance. On the other hand, if options are offered to the public to retain drug coverage at full insurance charges or to give up the coverage for lower charges, there may be a substantial portion of the public who would be willing to take the risk or to buy private drug insurance.

\subsection{Conclusions}

We have presented empirical evidence to show that the periodic reductions in drug prices were mostly on paper and that they were largely offset by providers who switched to more expensive drugs and used a larger number of drugs for the same patients. Drug companies have continually introduced "new" drugs into the market to replace "old" drugs, and the 
government has approved these "new" drugs at considerably higher reimbursement rates than those of the drugs they replaced.

We have also shown that there is strong evidence that physician drug choice is influenced by drug profit margins. In fact, our results suggest that if the profit margins of drugs disappeared overnight, total drug costs would be reduced by 20 percent to 50 percent. This reduction is achieved even when the probability of using a given drug remains unchanged and drug prices are kept constant. ${ }^{13}$

In 1998, in an attempt to move away from the current price regulation system, the government commission in charge examined a number of alternative drug pricing schemes and chose the reference price system. Under this system, producers first set list prices, and then the government sets a maximum reimbursement price for what it defines as a homogeneous group of drugs. The adoption of the reference price system was blocked at the last minute by strong opposition from JMA and drug companies. Apparently the government is not yet ready to move to a free market for drugs, but any option retaining elements of regulation presents its own set of problems, some of which are fairly serious.

\section{References}

Anegawa, Tomofumi. 1996. Basic research on pharmaceutical firms-A comparative study of European, U.S. and Japanese firms using patient data. Syakai-toIryou 5 (4): 49-63.

Ikegami, Naoki, Shunya Ikeda, Seiritsu Ogura, and Hiroki Kawai. 1998. Why medical care costs in Japan have increased despite declining prices for pharmaceuticals. PharmacoEconomics 14:97-105.

Innami, Ichiro. 1996. Nihonno iyakuhin-sangyou ni taisuru kenkyu-kaihatsuseisaku no kanouse (Towards a comprehensive R\&D policy package for the Japanese pharmaceutical industry). Syakai-to-Iryou 6 (2): 59-75.

Iryokeizai-kenkyu-kikou (Institute for Health Economics and Policy). Sizen-zou ni kansuru kenkyu (Report on natural increase in health care costs). Tokyo: Iryokeizai-kenkyu-kikou.

Ministry of Health and Welfare (MHW). 1994-1996. Shakai iryou shinryou koibetsu chosa (Survey of national medical care insurance services). 2 vols. Tokyo: Kosei Shou.

1994. Survey of drugs. Tokyo: MHW.

1995. Survey of drugs. Tokyo: MHW.

1996. Survey of drugs. Tokyo: MHW.

1999. Committee report. Tokyo: MHW.

13. Although these numbers are large, they are not outrageous. For instance, after the public insurance program began making lump-sum payments to health care providers for long-term elderly inpatients, the cost of injections reportedly dropped by almost 50 percent and the cost of drugs by almost 35 percent. These providers are no longer subject to economic distortions that induce them to give more drugs and shots to their patients. 
1999. Yakugi kogyo seisan dotai chosa tokei nenpo 1999 (Yearbook of production statistics of the pharmaceutical industry 1999). Tokyo: MHW.

Ben-Akiva, Moshe, and Steven Lerman. 1985. Discrete choice analysis: Theory and application to travel demand. Cambridge: MIT.

Nihon-seiyaku-danntai-rengoukai (Alliance of Pharmaceutical Manufacturers Association). 1997. Shin-iyakuhin soudanhinmoku yakkakizyun syusai itiranhyou (List of new drugs added to the drug price list through consultation). Tokyo: Nihon-seiyaku-dantai-rengoukai.

Ogura, Seiritsu, ed. 1996. Seifukanshou-kenkou-hoken no iryoukidoukou-nada ni kansura chosa-kenkyu (Analysis on the health care costs of health insurance managed by the government). Tokyo: Iroyokeisai-kenkyuu-kikou.

1998. Shizensou ni kansuru kenkyu houkokusyo (Report on natural increase in health care costs). Tokyo: Iryokeisai-kenkyuu-kikou.

Organization for Economic Co-operation and Development (OECD). 1998. OECD Health Data 1998. Paris: OECD.

Takayama, Noriyuki, ed. 1999. Koureika-syakai ni okeru koushi no yakuwaribuntan ni kansuru kenkyu houkokusyo (Report on the roles of public and private sectors in an aging society). Kourei-fukusi-kenkyukai. 
